\title{
Live Staining and Isolation of Specific Hormone-Producing Cells from Rat Anterior Pituitary by Cytochemistry with Lectins and Cholera Toxin B Subunit
}

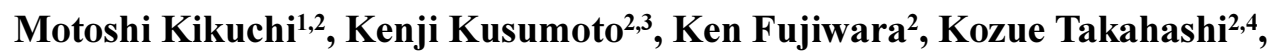 \\ Yukiko Tando $^{2}$ and Takashi Yashiro ${ }^{2}$ \\ ${ }^{1}$ Laboratory of Education, Jichi Medical University, ${ }^{2}$ Department of Anatomy, School of Medicine, Jichi Medical University, \\ Shimotsuke, Tochigi, Japan, ${ }^{3}$ Present address: Institute for Protein Research, Osaka University, Osaka, Japan and \\ ${ }^{4}$ Present address: Foods Laboratory, Kracie Foods, Ltd., Osaka, Japan
}

Received April 15, 2011; accepted June 9, 2011; published online July 20, 2011

\begin{abstract}
Anterior pituitary glands contain five types of hormone-producing cells. Distinguishing and isolating specific types of living cells are essential for studying their function. Although many such attempts have been made, the results have been disappointing. In the present study, we labeled specific types of living hormone-producing cells by using potential differences in sugar chains on the cell surfaces. Cytochemical analysis with lectins and cholera toxin $B$ subunit revealed that PNA, S-WGA, and cholera toxin $B$ subunit recognized sugar chains specific to prolactin cells, ACTH cells, and GH cells, respectively, and that UEA-I recognized most of prolactin cells and $\mathrm{GH}$ cells. Next, fluorescence-activated cell sorting was used to isolate $\mathrm{GH}$ cells labeled by fluoresceinated cholera toxin $\mathrm{B}$. The purity of the GH cell fraction estimated by immunocytochemistry and quantitative real-time PCR for cell type-specific genes was more than $98 \%$, which was higher than that reported in earlier studies, including those using transgenic animals. We conclude that cytochemistry with lectins and cholera toxin B subunit is a straightforward, acceptable method of isolating specific types of anterior pituitary cells and that the cells isolated by this method can serve as useful materials in the study of anterior pituitary cells.
\end{abstract}

Key words: lectin, cholera toxin, anterior pituitary, cytochemistry, cell sorting

\section{Introduction}

The pituitary gland is an endocrine organ that governs growth, reproduction, and homeostasis. The anterior pituitary gland contains five types of hormone-producing cells. Distinguishing and isolating specific types of living cells are important in investigating their specific functions, and many such attempts have been made. One method, density gradient centrifugation $[2,6,9,12]$, resulted in fractions of limited purity. Recently, transgenic techniques combined with fluorescence-activated cell sorting have achieved sufficient purity for specific cell types, but only a small

Correspondence to: Prof. Motoshi Kikuchi, Laboratory of Education, Jichi Medical University School of Medicine, Yakushiji 3311-1, Shimotsuke-shi, Tochigi 329-0498, Japan.

E-mail: kikuchim@jichi.ac.jp number of applications have been reported [7]. Cell lines established from anterior pituitary cells have yielded important findings [14]. However, because the original characteristics of the cell types are altered to some extent, these cells are not suitable for all types of research.

The extracellular surface of the plasma membrane contains carbohydrates as moieties of glycoproteins and glycolipids. Because these molecules participate in signaling, cell adhesion, and many other biological functions, the cell-surface carbohydrate moiety is thought to be specific to each cell type. Therefore, we aimed to label specific types of living hormone-producing cells by targeting potential differences in sugar chains. In this article, we present the results of our investigation of cell-surface sugar chains using of several types of lectin and cholera toxin B subunit and our findings regarding isolation of growth hormone cells by fluorescence-activated cell sorting. 


\section{Materials and Methods}

\section{Animals}

Male Sprague-Dawley rats aged 8 to 10 weeks were purchased from Japan SLC, Shizuoka, Japan. They were supplied food and water ad libitum and kept under a light cycle of $12 \mathrm{hr}$ light/12 hr dark. All animals were treated in accordance with The Guidelines for Animal Experimentation of Jichi Medical University, which is based on the NIH Guidelines for the Care and Use of Laboratory Animals.

\section{Primary culture}

The rats were perfused with $\mathrm{Ca}^{2+}$ - and $\mathrm{Mg}^{2+}$-free (CMF) Hanks' solution under deep Nembutal anesthesia. Anterior pituitary glands were excised and minced into pieces that were incubated in CMF Hanks' solution containing 1\% trypsin (Invitrogen, Carlsbad, CA, USA) and $0.2 \%$ collagenase (Nitta Gelatin, Osaka, Japan) for $15 \mathrm{~min}$ at $37^{\circ} \mathrm{C}$. Thereafter, tissue pieces were incubated in the same solution containing $5 \mu \mathrm{g} / \mathrm{ml}$ of DNase I (Boehringer-Mannheim, Mannheim, Germany) for $5 \mathrm{~min}$ at $37^{\circ} \mathrm{C}$. The digest was incubated in Hanks' solution containing $5 \mathrm{mM}$ ethylenediamine tetraacetic acid (Wako Pure Chemical Industries, Osaka, Japan) for $5 \mathrm{~min}$ at $37^{\circ} \mathrm{C}$. After washing, cells were dispersed in CMF Hanks' solution by gentle pipetting, then dispersed cells were separated from undigested tissue by filtering through nylon mesh (BD Biosciences, Bedford, MA, USA). In primary culture experiments, cells were suspended in M199 (Life Technologies) supplemented with 10\% fetal bovine serum (Sigma-Aldrich, St. Louis, MO, USA), 100 unit $/ \mathrm{ml}$ of penicillin, and $100 \mu \mathrm{g} / \mathrm{ml}$ of streptomycin and cultured, as described in Kusumoto et al. (2010) [10].

\section{Cytochemistry with lectins and cholera toxin B subunit}

Dispersed cells and cells in primary culture were rinsed with Hanks' solution and soaked in Hanks' solution containing fluorescein isothiocyanate-labeled lectins (10 or $20 \mu \mathrm{g} / \mathrm{ml}$, Vector Laboratories, Burlingame, CA, USA) and Alexa Fluor 594-labeled cholera toxin B subunit $(2 \mu \mathrm{g} / \mathrm{ml}$, Invitrogen) for $30 \mathrm{~min}$ at $4^{\circ} \mathrm{C}$. Twenty-one lectins were tested: concanavalin A (Con A), Dolichos biflorus agglutinin (DBA), peanut agglutinin (PNA), Ricinus communis agglu- tinin (RCA120), soybean agglutinin (SBA), Ulex europaeus agglutinin I (UEA I), wheat germ agglutinin (WGA), Griffonia simplicifolia Lectin I (GSL I), Lens culinaris agglutinin (LCA), Phaseolus vulgaris agglutinin E-form (PHA-E), Phaseolus vulgaris agglutinin L-form (PHA-L), Pisum sativum agglutinin (PSA), Sophora Japonica Agglutinin (SJA), Griffonia simplicifolia Lectin II (GSLII), Datura stramonium lectin (DSL), succinylated wheat germ agglutinin (S-WGA), Erythrina cristagalli lectin (ECL), Jacalin, Lycopersicon esculentum lectin (LEL), Solanum tuberosum lectin (STL), and Vicia villosa agglutinin (VVA). After incubation, cells were washed 3 times with Hanks' solution and observed using an IX-71 inverted fluorescence microscope (Olympus, Tokyo, Japan).

\section{Immunocytochemistry}

Cultured cells were fixed with $4 \%$ paraformaldehyde in $25 \mathrm{mM}$ phosphate buffer $(\mathrm{pH} \mathrm{7.4)}$ for $30 \mathrm{~min}$ at room temperature. The procedure for immunostaining was essentially the same as in Kikuchi et al., 2005 [8]. Primary antibodies used in experiments were rabbit anti-rat growth hormone (GH; Dr. K. Wakabayashi, Gunma University, Gunma, Japan, dilution of 1:12,800), anti-ovine luteinizing hormone (LH) $\beta$ subunit (Dr. K. Wakabayashi, dilution of $1: 12,800)$, anti-rat prolactin (NIH, Bethesda, MD, USA, dilution of 1:12,800), anti-rat thyroid-stimulating hormone (TSH) $\beta$ subunit (NIH, dilution of 1:3,200), anti-porcine adrenocorticotrophic hormone 1-39 (ACTH; Dr. Nakamura, Hokkaido University, Hokkaido, Japan, dilution of 1:3,200), and anti-S100B protein (DAKO, Glostrup, Denmark, dilution of 1:500). Secondary antibodies were goat anti-rabbit IgG conjugated with Alexa Fluor 488 or 568 (Invitrogen, dilution of 1:200). Specimens were observed using an AX80TX fluorescence microscope (Olympus).

\section{Fluorescence-activated cell sorting}

Cells $\left(1.0 \times 10^{6} \mathrm{cell} / \mathrm{ml}\right)$ stained with Alexa Fluor 488labelled cholera toxin B subunit, as mentioned above, were fractionated by a MoFlo cell sorter (DAKO) at a flow rate of 4,000 events/sec. Eluted cholera toxin B subunit-positive and -negative cells were collected in $15 \mathrm{ml}$-tubes containing $6 \mathrm{ml}$ of M199.

Table 1. Primers used in quantitative real-time $P C R$

\begin{tabular}{|c|c|c|c|}
\hline & Forward/reverse primer $\left(5^{\prime} \rightarrow 3^{\prime}\right)$ & $\begin{array}{l}\text { Product size } \\
\quad(\mathrm{bp})\end{array}$ & $\begin{array}{c}\text { GeneBank } \\
\text { accession number }\end{array}$ \\
\hline Proopiomelanocortin & AGGACCTCACCACGGAAAGGTCAAGGGCTGTTCATCTCC & 109 & NM_139326.2 \\
\hline TSH $\beta$ & CGTGCTTTTCGCTCTTGCTTTGGTCAGGCAGTAGGCACAC & 101 & NM_013116.1 \\
\hline $\mathrm{GH}$ & CAAGAGGCTGGTGCTTTACCAATGTAGGCACGCTCGAACT & 123 & NM_001034848.1 \\
\hline Prolactin & CATCAATGACTGCCCCACTTCGAGTGCACCAAACTGAGGATCA & 108 & NM_012629.1 \\
\hline $\mathrm{LH} \beta$ & CATCACCTTCACCACCAGCAGGTAGGTGCACACTGGCTGA & 101 & NM_012858.1 \\
\hline FSH $\beta$ & TACTGCTCCTTCGGTGAAATGAGCAGACCCAGACATTTTGGATAT & 110 & XM_342485.1 \\
\hline $\begin{array}{l}\text { Common } \alpha \text {-subunit of } \\
\text { glycoprotein hormones }\end{array}$ & CCAAATCATTTACTAAGGCCACACCTTGGCACACATGGAAGCT & 113 & ВC063160.1 \\
\hline S- $100 \beta$ protein & ATAGCACCTCCGTTGGACAGTCGTTTGCACAGAGGACAAG & 132 & NM_013191.1 \\
\hline$\beta-2$ microglobulin & AAGTTGGGCTTCCCATTCTCCCGTGATCTTTCTGGTGCTT & 109 & NM_012512.1 \\
\hline
\end{tabular}




\section{Quantitative real-time PCR}

Total RNA was extracted by Trizol reagent (Invitrogen) and incubated with RNase-free DNase I (Promega, Madison, WI, USA). Complementary DNA was synthesized from total RNA by using a PrimeScript RT reagent kit (Takara Bio, Shiga, Japan). Quantitative real-time RT-PCR was performed according to our previous report [4]. The reaction was performed with SYBR Premix Ex Taq (Takara Bio) using ABI PRISM 7900HT (Applied Biosystems, Carlsbad, CA, USA). We used the beta-2 microglobulin gene expression to normalize the amount of cDNA in the samples. The primers used in the reactions are shown in Table 1.

\section{Results}

\section{Cytochemistry with lectins and cholera toxin B subunit}

Primary cultures of anterior pituitary cells were treated with 21 lectins that were conjugated with FITC and cholera toxin B subunit conjugated with Alexa Fluor 594. Of the 21 lectins tested, ConA, RCA120, WGA, LCA, PHA-E, PSA, and Jacalin bound to all anterior pituitary cells. In contrast, DBA, DSL, LEL, GSL I, and PHA-L showed no affinity for any anterior pituitary cells. Nine lectins-PNA,
ECL, SJA, STL, GSL-II, UEA-I, VVA, SBA, and S-WGAand cholera toxin $\mathrm{B}$ subunit showed selective binding to some part of the cells. Using these 10 probes, further immunocytochemistry for hormones revealed that PNA bound specifically to prolactin-producing cells (Fig. 1A and B) and that cholera toxin B subunit bound specifically to GH-producing cells (Fig. 1I and J; Fig 2). S-WGA bound weakly to many cells and strongly to ACTH-producing cells (Fig. 1C and D). UEA-I bound to most prolactin-producing cells and GH-producing cells (Fig. 1E-H). ECL, SJA, STL, GSH-II, VVA, and SBA did not show affinity for specific cell types. The results of cytochemistry with lectins and cholera toxin B subunit with regard to cell types determined by immunocytochemistry are shown in Table 2 . In addition, the stainability of prolactin-producing cells with PNA was poor immediately after trypsin treatment but increased during culture, while the stainability of ACTH-producing cells and GH-producing cells with S-WGA and cholera toxin B subunit, respectively, was not affected by trypsin treatment (data not shown). These findings suggest that PNA bound to glycoprotein and that both S-WGA and cholera toxin B subunit bound to glycolipid or trypsinresistant glycoprotein.
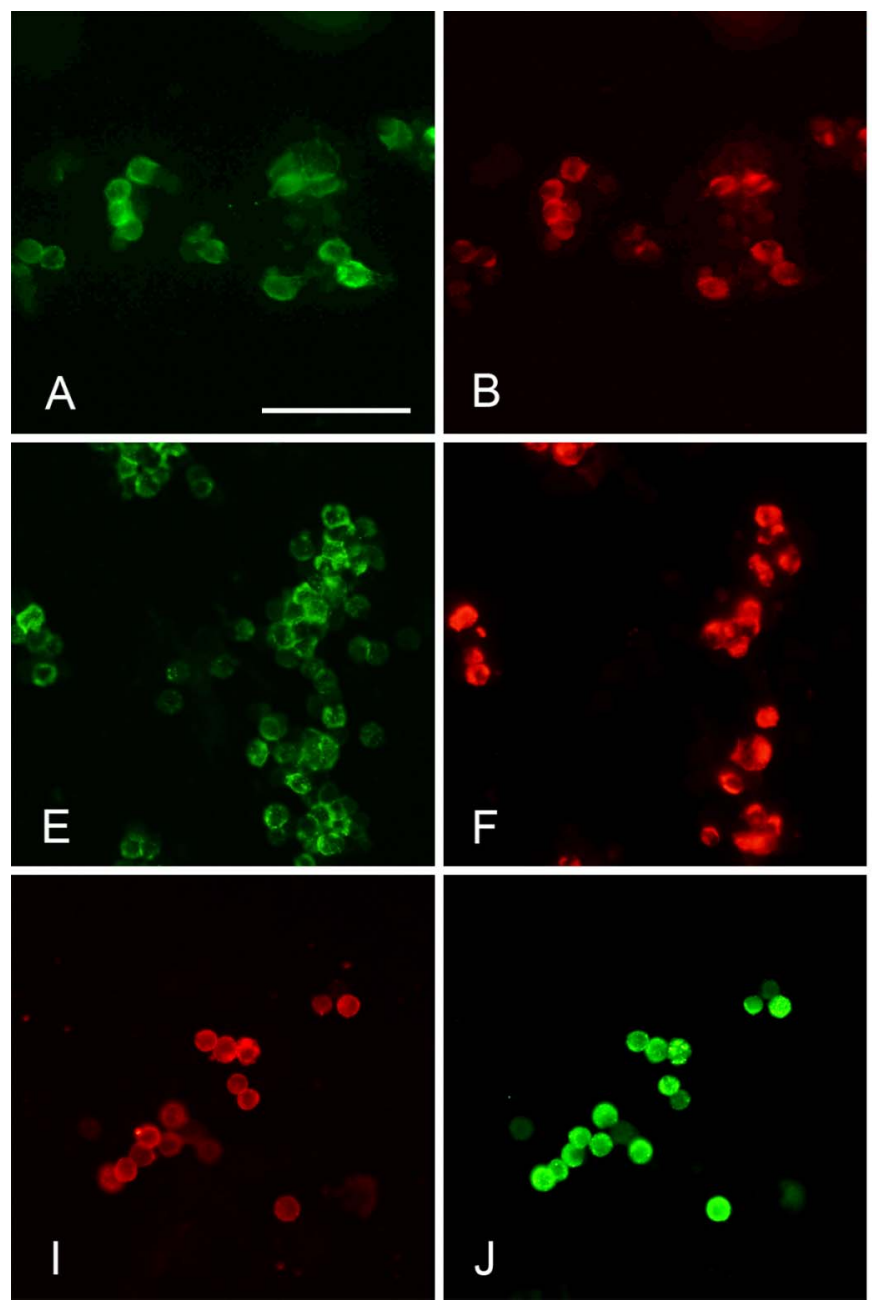
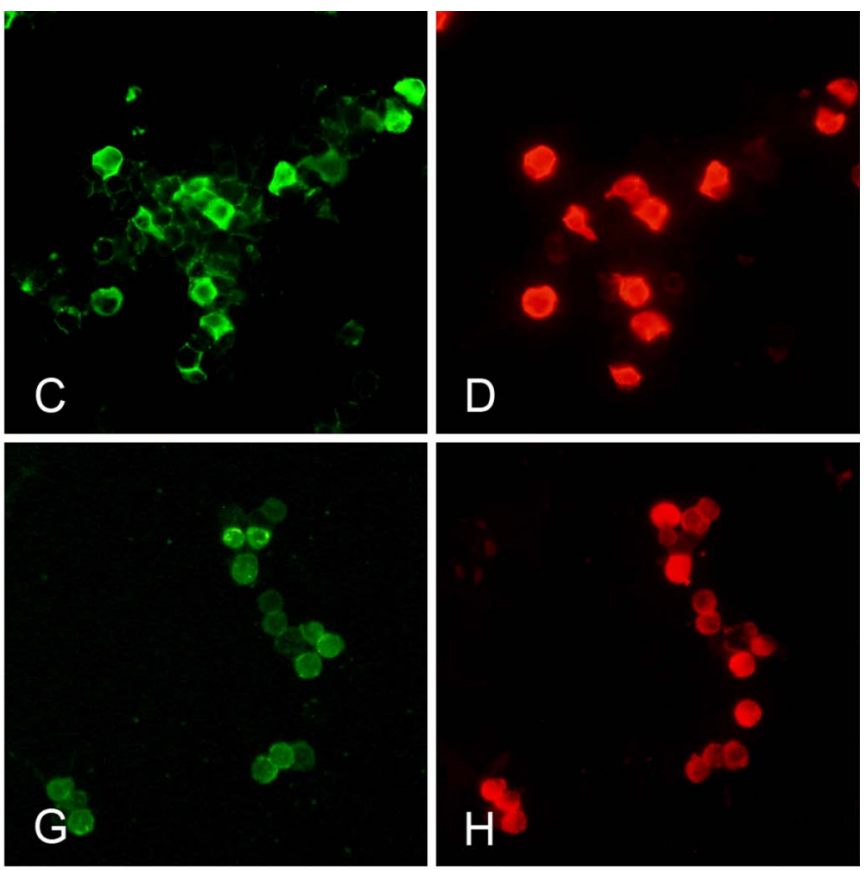

Fig. 1. Cytochemistry with lectins and cholera toxin B subunit. Anterior pituitary cell primary culture was stained with fluorescein isothiocyanate-labeled lectins (green) and Alexa Fluor 594-labeled cholera toxin B subunit (red), fixed, and then subjected to immunocytochemistry for hormones (red or green). Only combinations with double-positive cells are shown. The probes were (A, B) PNA and prolactin, (C, D) S-WGA and ACTH, (E, F) UEA I and prolactin, $(\mathbf{G}, \mathbf{H})$ UEA I and GH, and (I, J) cholera toxin B subunit and GH. $\mathrm{Bar}=100 \mu \mathrm{m}$. 

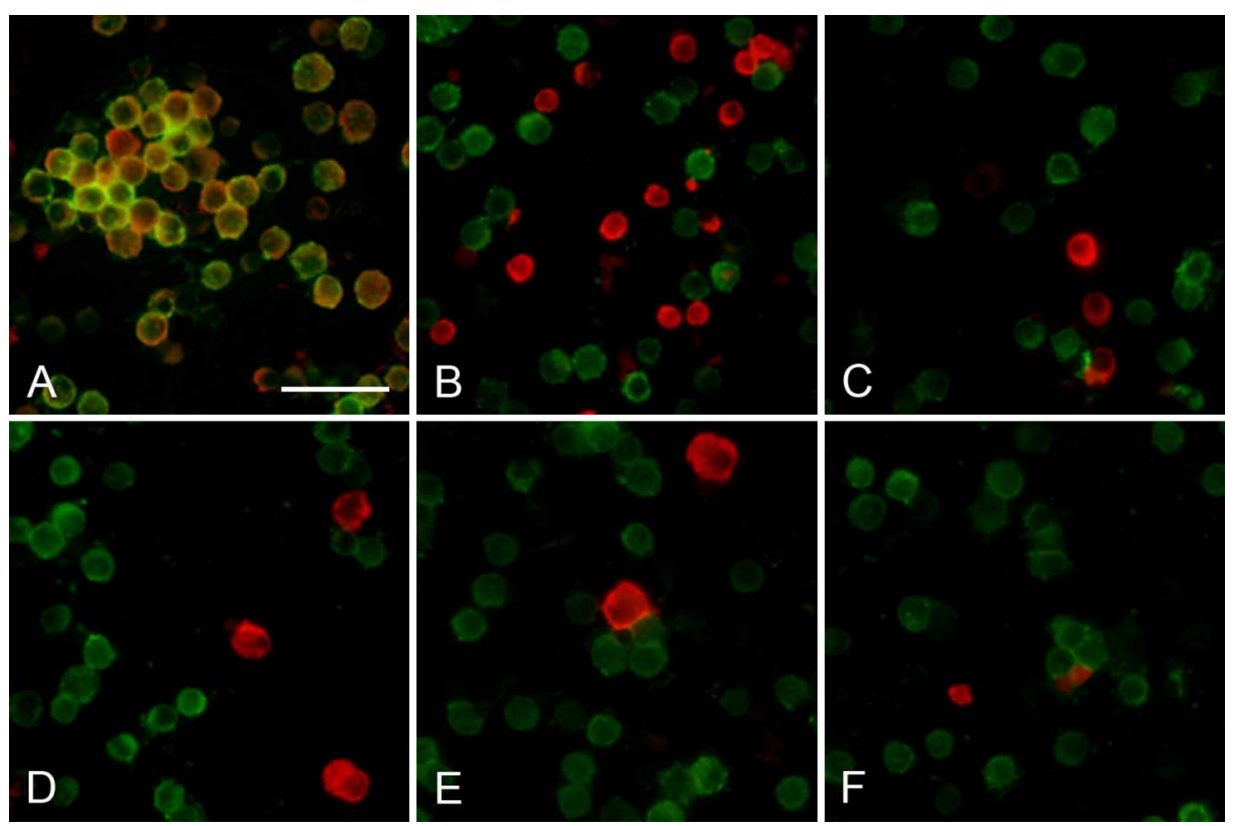

Fig. 2. Double fluorescence staining of anterior pituitary cell primary culture using cholera toxin B cytochemistry (green) and immunocytochemistry for 5 types of hormones and S-100B protein as a marker of folliculo-stellate cells (red; A: GH, B: Prolactin, C: LH, D: ACTH, E: TSH, F: S-100B protein). Bar $=100 \mu \mathrm{m}$.

Table 2. Numbers of positive cells on cytochemical analysis with lectins and cholera toxin B subunit per 100 hormone-producing cells of each type

\begin{tabular}{lrcccc}
\hline \multicolumn{1}{c}{ Probe } & GH & Prolactin & LH & TSH & ACTH \\
\hline Cholera toxin B & 100 & 0 & 1 & 0 & 0 \\
PNA & 1 & 98 & 0 & 0 & 0 \\
S-WGA & 1 & 1 & 0 & 1 & 93 \\
UEA I & 74 & 40 & 0 & 0 & 0 \\
\hline
\end{tabular}

\section{Isolation of GH cells by fluorescence-activated cell sorting}

After determining that the cholera toxin B subunit specifically recognizes GH cells specifically, we attempted to use fluorescence-activated cell sorting to isolate $\mathrm{GH}$ cells from dissociated anterior pituitary cell suspensions after staining of the fluoresceinated cholera toxin B subunit. The elution pattern of the cells is shown in Figure 3C. Approximately $40 \%$ of cells were fractionated in R2 and $30 \%$ in $\mathrm{R} 3$. The results of immunocytochemical analysis of the R2 and R3 fraction of GH are shown in Figure 3A and B. More than $98 \%$ of cells in R3 were GH cells; LH cells and prolactin cells were rarely detected in $\mathrm{R} 3$ (frequency $<1 \%$ ). In contrast, $\mathrm{GH}$ cells were not detected in the $\mathrm{R} 2$ fraction.

\section{Quantitative real-time PCR}

To assess the purity of R2 and R3 fractions, real-time PCR was used to quantify expressions of cell type-specific genes, GH, prolactin, POMC, TSH $\beta$ subunit, LH $\beta$ subunit, FSH $\beta$ subunit, common $\alpha$-subunit of glycoprotein hormones, and S-100 $\beta$ protein. Expression levels were expressed as a percentage of the total expression level of the gene in Figure 3D.

\section{Discussion}

Utilizing cytochemical analysis with lectins and cholera toxin B subunit, we succeeded in labeling living $\mathrm{GH}$, PRL, and ACTH cells for the first time. Furthermore, we demonstrated that cytometry can isolate labeled GH cells with high purity.

Cytochemistry with lectins and cholera toxin B subunit revealed that PNA, S-WGA, and cholera toxin B subunit recognized specific surface sugar chains on prolactin cells, ACTH cells, and GH cells, respectively. UEA-I recognized most prolactin cells and GH cells. According to the known specificities of lectins and cholera toxin B subunit, we can infer that prolactin cells have a sugar chain containing Galß1-3GalNAc and ACTH cells have (GlcNAc)n on the cell surface, and that GH cells possess ganglioside GM1. Similarly, most prolactin cells and GH cells appear to have sugar chains containing Fuc $\alpha 1-2$ Gal $\beta 1-4 G l c N A c$. Our result showing that GH cells possess ganglioside GM1 might be related to findings from a report by Cox et al. (1999), which showed that mutation of ganglioside GM1 resulted in GH insufficiency in cats [3].

Differentiation of hormone-producing cells in the anterior pituitary is regulated by various transcriptional factors [15]. Studies of the relationship between the differential patterns of cell-surface carbohydrates and transcriptional factors are likely to augment our understanding of anterior pituitary cell differentiation. 


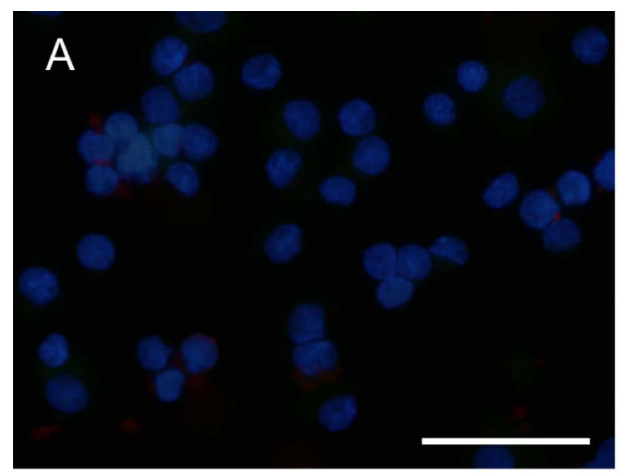

C

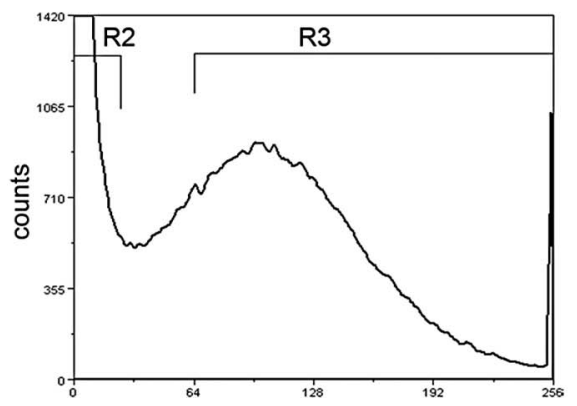

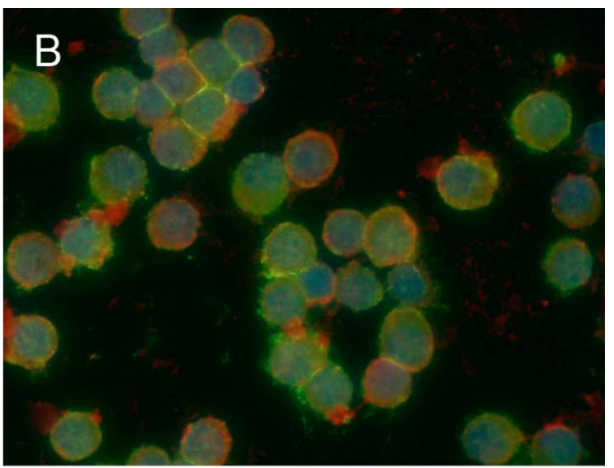

D

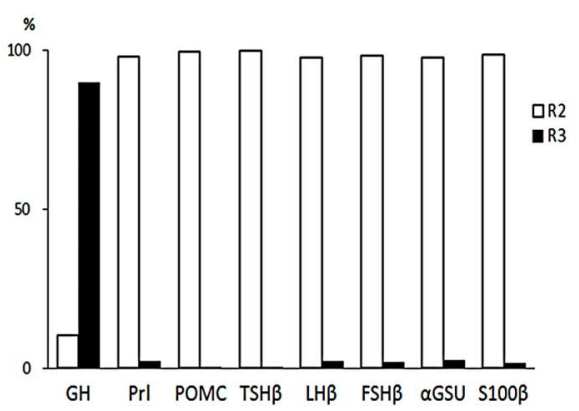

Fig. 3. Analyses of cholera toxin B-negative (R2) and -positive (R3) cell fractions after fluorescence-activated cell sorting. Immunocytochemistry of the R2 (A) and R3 (B) fractions for GH (red). Results of staining with cholera toxin B and Hoechst 33258 are shown in green and blue, respectively. No cells in the R2 fraction and nearly all cells in the R3 fraction were GH-positive. (C) Elution pattern of cells after fluorescence-activated cell sorting. The x-axis represents the fraction number. (D) Quantitative analysis of various gene expressions in the R2 (empty columns) and R3 (solid columns) fractions on real-time PCR. The y-axis represents expression of each gene in the R2 and R3 fractions as a percentage of the total expression level of the gene. Prl: prolactin, POMC: proopiomelanocortin, $\alpha$ GSU: common $\alpha$-subunit of glycoprotein hormones, S100ß: S-100B protein as a marker of folliculo-stellate cells. Bar=50 $\mu \mathrm{m}$.

In previous research, density gradient centrifugation has been used to isolate specific hormone-producing cells (prolactin and GH cells: [2], prolactin cells: [6], LH cells: [12], GH cells: $[11,13,16])$. The purities of fractions did not exceed $75 \%$, and the fractions were referred to as specific cell type-"enriched" fractions. Folliculo-stellate cells are another component of anterior pituitary cells and do not produce hormones. They were also isolated by density gradient centrifugation by Baes et al. (1987), with a reported purity of $66 \%$ [1]. Recently, recognition of specific cell types has been facilitated by transgenic techniques, in which cDNA encoding green fluorescence protein is conventionally introduced under a specific promoter region. Ishida et al. (2007) attempted prolactin cell separation by cell sorting in a transgenic mouse [7]. Our research group also reported cell sorting results in GFP transgenic rats under promoter of S-100 $\beta$ protein, which is a marker of folliculo-stellate cells [5], although purity was not measured. In the present study, after determining mRNA levels (Fig. 3D) and the proportion of each cell type with respect to the total number of cells in the anterior pituitary, we estimated that the purity of GH cells in fraction R3 exceeded 98\%. The immunocytochemical results described above lend further support to our estimate. This purity is higher than that reported for prolactin cells (90\%) by Ishida et al. (2007) in their study using a transgenic technique [7]. In addition to GH cells, small numbers of LH cells were positive in cholera toxin B subunit cytochemistry. However, because staining intensity was usually higher in GH cells than in $\mathrm{LH}$ cells, it was possible to reduce contamination by LH cells in fraction R3 to below $1 \%$. In addition, the proportion of $\mathrm{GH}$ cells in fraction R3 recovered from all GH cells applied to the cell sorter was approximately $60 \%$.

In the present report, we described a straightforward, acceptable method to isolate GH cells. We confirmed that isolated GH cells remained healthy in culture for at least 3 days (data not shown). Furthermore, it is likely that prolactin and ACTH cells can be isolated by using a similar protocol. The ability to isolate such cells would be a significant contribution to the study of anterior pituitary gland.

\section{Acknowledgments}

We thank David Kipler, ELS of Supernatant Communications for revising the language of the manuscript. This work was supported in part by a Grant-in-Aid for Scientific Research from the Ministry of Education, Culture, Sports, Science and Technology of Japan to MK (19590194) and TY (22590192). 


\section{References}

1. Baes, M., Allaerts, W. and Denef, C. (1987) Evidence for functional communication between folliculo-stellate cells and hormone-secreting cells in perifused anterior pituitary cell aggregates. Endocrinology 120; 685-691.

2. Bollengier, F., Velkeniers, B., Hooghe-Peters, E., Mahler, A. and Vanhaelst, L. (1989) Multiple forms of rat prolactin and growth hormone in pituitary cell subpopulations separated using a Percoll gradient system: disulphide-bridged dimers and glycosylated variants. J. Endocrinol. 120; 201-206

3. Cox, N. R., Morrison, N. E., Sartin, J. L., Buonomo, F. C., Steele, B. and Baker, H. J. (1999) Alterations in the growth hormone/ insulin-like growth factor I pathways in feline GM1 gangliosidosis. Endocrinology 140; 5698-5704.

4. Fujiwara, K., Maekawa, F., Kikuchi, M., Takigami, S., Yada, T. and Yashiro, T. (2007) Expression of retinaldehyde dehydrogenase (RALDH)2 and RALDH3 but not RALDH1 in the developing anterior pituitary glands of rats. Cell Tissue Res. 328; 129-135

5. Horiguchi, K., Kikuchi, M., Kusumoto, K., Fujiwara, K., Kouki, T., Kawanishi, K. and Yashiro, T. (2010) Living-cell imaging of transgenic rat anterior pituitary cells in primary culture reveals novel characteristics of folliculo-stellate cells. J. Endocrinol. 204; 115-123.

6. Hu, L. and Lawson, D. (1994) Distribution of lactotroph subpopulations in different regions of the rat pituitary. Life Sci. 55; 1553-1559

7. Ishida, M., Takahashi, W., Itoh, S., Shimodaira, S., Maeda, S. and Arita, J. (2007) Estrogen actions on lactotroph proliferation are independent of a paracrine interaction with other pituitary cell types: a study using lactotroph-enriched cells. Endocrinology $148 ; 3131-3139$

8. Kikuchi, M., Sunaga, K., Yatabe, M., Takigami, S., Sakamoto, A. and Yashiro, T. (2005) An in vivo and in vitro immunohistochemical study of integrin alpha subunit localization in the rat anterior pituitary. Acta Histochem. Cytochem. 38; 381-386.
9. Kim, S. U., Shin, D. H. and Moretto, G. (1985) Isolation, culture and cell-type identification of adult human pituitary cells. Acta Neuropathol. 68; 205-208.

10. Kusumoto, K., Kikuchi, M., Fujiwara, K., Horiguchi, K., Kouki, T., Kawanishi, K. and Yashiro, T. (2010) Effect of E-cadherin expression on hormone production in rat anterior pituitary lactotrophs in vitro. Acta Histochem. Cytochem. 43; 83-88.

11. Lafarque, M. M., Ezquer, M., Aguado, L. I. and Oliveros, L. B. (2004) Bovine pars tuberalis secretions release growth hormone from rat pars distalis of pituitary gland. Neuro Endocrinol. Lett. 25; 273-277.

12. Lafarque, M. and Oliveros, L. (2008) A 66-kDa protein of bovine hypophyseal Pars tuberalis induces luteinizing hormone release from rat Pars distalis. Biocell 32; 211-218.

13. Lindstrom, P. and Savendahl, L. (1996) Enrichment of type I and type II rat somatotrophs: characterization of growth hormone secretion in vitro. Endocrinology 137; 4174-4180.

14. Ooi, G. T., Tawadros, N. and Escalona, R. M. (2004) Pituitary cell lines and their endocrine applications. Mol. Cell. Endocrinol. $228 ; 1-21$

15. Osamura, R. Y., Egashira, N., Kajiya, H., Takei, M., Tobita, M., Miyakoshi, T., Inomoto, C., Takekoshi, S. and Teramoto, A. (2009) Pathology, pathogenesis and therapy of growth hormone (GH)-producing pituitary adenomas: technical advances in histochemistry and their contribution. Acta Histochem. Cytochem. 42; 95-104.

16. Swennen, L., Baes, M., Schramme, C. and Denef, C. (1985) Beta-adrenergic stimulation of adenosine-3',5'-monophosphate (c-AMP) in primary cultures of rat anterior pituitary cell populations separated by unit gravity sedimentation. Relationship to growth hormone and prolactin release and to nonsecreting cells. Neuroendocrinology 40; 78-83.

This is an open access article distributed under the Creative Commons Attribution License, which permits unrestricted use, distribution, and reproduction in any medium, provided the original work is properly cited. 